\title{
The Prospects of E-Learning in School Education
}

\author{
Amani M. Albarkati \\ Saudi Arabia
}

\begin{abstract}
The main and one of the curriculum or prospectus goals of elearning in school edification is to cultivate apprentices for 21 st century aptitudes through their consistently erudition works out. From previous studies in the related fields demonstrates that K-12 schools should take in e-learning sense of how to extend learning odds of apprentices/students for the change of 21 st century aptitudes. Six examination problems vital for e-learning in school education has been perceived, to be particular the affirmation of making 21st century aptitudes of apprentices; the traverse or bridging of the gap/breach between instructive modules in school and circumstances in general society eye; the enhancement of learning prospects in the learning development; the amassing of evidence of progress and constructing cognizance of headway; the evaluation of 21 st century capacities; and the acquisition of educator transformation for enculturating learners to make 21 st century capacities and aptitudes. Several other authors applaud the huge accomplices across over different countries to ponder strategies on the target setting of curriculum or instructive projects tending to 21 st century aptitudes revolution and associating fissure amidst society and school; on the convenience of ICT for school edification; on the security concerns of learning data in e-learning process; and on the pre-service or in-service educator/instructor progression. In this paper we discuss the investigation concerns and strategy insinuations or suggestions essential for realizing such an instructive projects objective.
\end{abstract}

\section{Keywords}

E-learning, School Education, Strategies, Guidelines

\section{INTRODUCTION}

The support of learner-centered learning/erudition and the ascent of modernized classrooms lead to the enthusiasm for change of pedagogical or academic design that sponsorships the headway of 21 st century capacities through domain knowledge learning. An International Research Network (IRN) "Theory and Practice of Pedagogical Design for Learning in Digital Classrooms" has been recognized under the World Educational Research Association (WERA) for the communitarian tries of practice-driven investigation for constructing theories that exhort and direct the academic setup or design supportive for effective association of learning in digital and modern classrooms. The rising inclination is antedate toward a more personalized and group situated learning in institute edification; where corporeal classrooms retain its centrality in apprentices' affiliation and socialization, however learning encompassing outdoor classrooms will accept a more key part in apprentices' acquaintance advancement. We will presumably admonish researchers and governments transversely over different countries to ponder associated investigation problems and to make and realize far reaching e-learning game plans exclusively; and after that to blowout and build up the impact of modern digital classrooms for K-12 schools learner-centered learning.

\section{E-LEARNING PROSPECTS IN SCHOOL EDUCATION}

The attractiveness and reputation of digital technology progresses the exploitation of ICT instruments for learning in school edification. To take advantage of this cutting edge learning, learners or students need solicitation and essential reasoning capacities to pick and get ready important and tried and true information from fluctuating hotspots for learning [1][2]. Students or Learners similarly require correspondence and joint exertion capacities to talk and cooperate with their friends to complete errands and share results [3][4]. These aptitudes are significant parts of 21 st century capacities, which endow apprentices to adequately get data and progress learning in the 21st century [5][6]. It is in this way anticipated the learning destinations of school education in the prospective years need to discourse the headway of $21 \mathrm{st}$ century aptitudes beyond learning knowledge domain curricular objectives. Both 21st century aptitudes and domain knowledge are the learning results to be concerned in the learning targets for making 21 st century capacities. As like domain knowledge, students' ability in 21 st century aptitudes is moreover ought to have been considered amid the time spent in classroom learning [7][8]. 21st century capacities valuation therefore ought to be associated with the domain knowledge examination, so instructors can better grasp the interrelationship between learners' increments in these two sorts of learning results. The associated evaluation should center at confirmation of progress and thoughtfulness regarding advance, remembering the finished objective to divulge both optimistic and undesirable segments of learning method [9]. The modernized gadgets exercised in digital classrooms can track and store capacious information on apprentices' joint effort. Such imaginative sponsorship can energize a supportive and methodical record, recuperation and commenting on apprentices' information on learning process and learning results. Learners subsequently can collect learner-centered learning information and make learnercentered learning portfolio or collection. Instructors subsequently can give propitious response via learning results [10]. It is anticipated that in the prospective years, the school education division over the world needs to get arranged for the generation of digital classrooms which upkeep or prop up apprentices to enough make 21 st century aptitudes as the progressive learning process. The institution of digital resources, propelled strategies for correspondence and digital platforms for learning and educating understands various prospects to overhaul the learning process in school edification in the 21 st century. It is expected that such learning method is reinforced by resources in mechanized or digital and non-propelled/digital structures impeccably inside and outside of digital classrooms [11] in which apprentices consistently exercise flexible computing devices and social learning frameworks for the recuperation, decision, and sharing of true blue information from various sources [10][12][13]. The learning process for making 21st century capacities is depicted of three highlights. Its first highlight is capacities change in both formal and easygoing learning 
settings [14][15] The students will be involved with a steady learning setting to soundly apply distinctive non particular aptitudes for in-school teacher-led learning process began in automated classrooms and after-school learner-imitated learning process in social learning stages/instruments according to discrete requirements [16] [17] [18]. Its second emphasis is aptitudes headway through both personalized and synergistic learning tactics. In solitude or with partners, learners will take commitments to put on distinctive non particular aptitudes for orchestrating targets, realizing assignments, watching propels and evaluating results in their learning process [19][20]. The information for learners will be in an unimportant however sufficient total for perceiving solitary desires and heading for imminent change [21][22][23]. Its third highlight is capacities progression reinforced by verification of progress and awareness of headway. The learning process in the e-learning circumstances can be laid out in an extent of accomplishments in legitimate learning associations. Opulent affirmation of progress and valuable dissatisfaction could be accumulated from learners' execution in the midst of the learning system of which can be signs on applying 21st century aptitudes for taking care of honest to goodness information, considering basic intuition ways, enunciating suggested data and masterminding diverse examination perspectives for learning advancement [24][25][26] Students and instructors would then have various chances to explore affirmation of progress and reflection on regard for development in the e-learning circumstances which fuse all and more than those influential examinations consistently over the learning process and the combined calculations at precise periods. Development or ICT expect a dire part in supporting schools on understanding the appealing learning goals, learning process and learning results. Students currently have various conduits to get to modernized or digital resources and take in them for correspondence to connect with sidekicks for e-learning. This opens learners to various open entryways for applying $21 \mathrm{st}$ century capacities in the ICT maintained learning process. To incite learners to be valued by such learning prospects, there ought to be conclusive examination revelations and solid plan exercises perfect to the joining of e-learning parts in instructive projects transport, with a particular final objective to drive K-12 schools to suspect the instructive modules objective charming for the headway of 21 st century aptitudes among learners through the learning process in e-learning circumstances. The learning process in e-learning circumstances, as discussed, is required to contemplate three key parts for boosting learning prospects supportive for $21 \mathrm{st}$ century aptitudes change. The fundamental segment of blending formal and easygoing learning approaches helps schools to interface the present breach between school instructive modules and society circumstances. The second part of changing individualized and synergistic learning helps learners to extend consideration regarding learning realization on individual basis besides fabricate motivation to pick up learning ground with allies. The third segment of get-together affirmation of progress and building cognizance with headway comforts educators and learners to grasp levels of learning results on the formative reason and after that settle on taught decisions on next instructing and learning contest. Giving learners individualized computing devices with remote accessibility for getting to modernized resources, and outfitting learners and teachers with cutting edge learning gadgets for taking after and securing learning data are imaginative sponsorships incredible to the affirmation of these three key parts in the learning process for making 21 st century aptitudes inside and outside of digital classrooms. Research inputs and technique masterminding in association with the three key parts and the two sorts of inventive sponsorships are truly required for the strategy of dynamic, important and insightful learning in ICT equipped classrooms. Apprentices will make learning results similarly as both domain knowledge and 21st century aptitudes in the previously stated learning process. Research community ought to look at the suitable ways to deal with overview 21 st century capacities on top of domain knowledge at different periods of such learning process, with a particular finished objective to reinforce K-12 schools on the fitting and real-time estimation of learners' data and aptitudes change. The powerful execution of the previously stated learning process obliges instructors to comprehend the vision of progressing 21 st century capacities among learners; expert the aptitudes in empowering rapid, accommodating and natural learning process among learners; pro the game plan of automated and non-mechanized resources; and see/perceive the equal the initial investment with centrality of insightful achievement and 21 st century aptitudes as learning results in school learning. The present teacher progression related to e-learning must be changed as per get prepared educators to change their feelings and practice in these four edges [27]. The focal point of such similarity will be put on the impact of the teacher change programs on instructors motivational change and after that practice changes for learner-centered learning, yet not only the compromise of IT practice or imaginative/ICT sponsorship in the transport of instructor progression programs. One basic focal point of future instructor progression program, as indicated, is the coordination of benefits in automated and customary non-mechanized structure for supporting learning and training in electronic classrooms [28]. Course of action implies how an educator administers, logically, multi-layered activities in a multi-goals setting [29]. Bearing in mind that educators disregard to grasp various investigation based learning developments, the coordination view advantages, the methodology of assignment and conformity with a final objective to bring the issues of practice into center premium.

\section{RESEARCH PROSPECTS}

So far six research problems are seen as essential for grasping the changes in the objective, process and aftereffect of learning in school education environment in the prospective years. The primary problem relates to the affirmation of learning goal of making learners/students for 21st century aptitudes. The researchers so as to gather can contribute in such way verification based investigation which decidedly recognizes variables that move school pioneers to change school-based orchestrating need with regards to the $21 \mathrm{st}$ century capacities. These investigation tries intend to lift school pioneers to truly see the favorable circumstances for $\mathrm{K}$ - 12 learners who controlling 21 st century capacities; hence to make a move to bargain precedence to the change of $21 \mathrm{st}$ century aptitudes when drawing up school-based plans for elearning joining into instructive projects provision, and furthermore ask for campus-wide accord on this organizing course for a charming instructive modules utilization. The second research concern relates to the spreading over of the gap or breach between schools' instructive projects movement and society's realistic circumstances. In the knowledge and competency-organized society, learners are asked for on applying knowledge across over diverse branches of knowledge for dealing with ordinary issues in the home and gathering circumstances. The researchers so as to gather can contribute in such way K-12 schools to truly bond the content 
of school instructive modules passed on to learners and the utilization of domain knowledge acquired by learners. One of the auspicious heading is propelling the development of digital classrooms in K-12 schools to open learners to the genuine and contextualized learning circumstances for propelling scholarly engagement, from the perspective of cognitive realism. Cognitive realism in the field of education implies the method of submerging and attracting understudies in the use of proliferation materials for complex learning endeavors for sensible and realistic problem solving [30][31]. The investigation gathering could impel K-12 schools to regard the achievement of cognitive realism in subject learning, with an importance on learning circumstances with various results and learning endeavors on higher-order intellectual, and thusly induce instructors to pick fitting propelled resources for propping up learners, devoid of instructor mediation, to explore, think, pick and perform the steps that a master would take to deal with multifaceted issues of the themes of the subject. The third research subject recounts to the affirmation of learning system of making learners for 21 st century aptitudes. The powerful progression of learners' 21 st century aptitudes asks for the viewpoint change to learner-centered learning in electronic classrooms. It apprehends the suitability and essentialness problems of instructive modules provision, in order to facilitate learners to palatably get to resources and circumstances that are associated to real life problem solving when they make $21 \mathrm{st}$ century aptitudes. Educators consequently need to revolve their schooling inspirations and educational training for driving learners in two courses such as engaging in dynamic, accommodating and astute learning process for their application and impression of 21 st century capacities in school edification, and raising their social care among the learning frames in school, in gathering and in home milieu. The investigation gathering can contribute in this point of view by looking at e-learning models that instruct K-12 schools concerning the promising approach to manage imaginative practice and educational arrangements at classroom level for blending formal and easygoing learning approaches, making solid and contextualized learning settings, and changing individualized response acquisition and selffacilitated learning process. The fourth research matter or problem re-counts to assembling verification of progress and building awareness with headway for supporting pedagogical/educational decision making of educators and enlarging learning odds of learners in making 21 st century aptitudes in the learning process. The sponsorship of learners' dynamic learning and the example of automated classrooms putting into practice distinctive learning management systems and social network platforms put novel demands on instructors for changing educational practices in school edification. Data mining frameworks are created customarily to gather broad size of data, removing huge samples, and get intellectual acquaintance [32]. The incorporation of data mining practices into the learning analytics platform considers an exact and persistent philosophy in perceiving effective pedagogical changes [33]. In any case, the information from learning analytics have not yet all around exercised to educate learning and training on the grounds that with respect to various reasons [34]. One reason is that a respectable part of the data open to learners and educators will be not able instruct pedagogical decision making following unfathomable scale assessment data are by and large not associated with learners' learning systems/processes and results. One more cause is that the technologies brought into play to track learners' erudition typically focus on activity taking after as opposed to knowledge taking after or tracking, which don't guide learners and instructors to recognize learning concerns and settle on right decision making to discourse these concerns. Thusly, attempts are required for pros to discover techniques to endow learning analytics for accumulating confirmation of progress and building awareness of headway among learners for legitimate educational decision making in e-learning circumstances in school education. The fifth research defy re-counts to the evaluation of learning results of making learners for 21 st century aptitudes. As both domain knowledge and 21st century aptitudes are the learning results to be fretful in electronic classrooms in school education, there ought to be a sound and formative approach for the examination of 21 st century capacities despite domain knowledge. The investigation pros and community so as to gather can contribute by reviewing the ways to prop up schools to practice IT for assessing 21st century aptitudes with an association with domain knowledge. The sixth research concern re-counts to the instructor headway for urging learners to make $21 \mathrm{st}$ century aptitudes. The investigation pros and community can make relating input in two ways. In any case, scholastics can bargain instructor progression programs which familiarize teachers with the latest change of speculative frameworks and convenient strategies on progressing 21 st century capacities in e-learning circumstances, and give educators support went from fullscripting stages for less talented teachers to less-scripting systems for more capable instructors. Second, academics or scholastics can examine the versatile and sensible teacher development models that develop instructor's ability to propel learner's 21 st century capacities. The models are depended upon to support first the sensible joint exertion between K-12 schools and research bunch for longitudinal revisions that facilitate teachers to iteratively arrangement, apply, reflect and refine their educational practice for recognizing learnercentered learning in cutting edge classrooms; and after that the versatile sharing amid educators in K-12 schools inside the same school and a while later over the school bunch that teachers lead capable change in solitude to upgrade competency in sorting out training and learning in ICT equipped classrooms.

\section{STRATEGY RECOMMENDATIONS}

Bearing in mind aforementioned statements, four sorts of authoritative methodology provisions has been recommended, at confined and overall levels, for the pragmatic and versatile progression of ICT based classrooms in school education in near future.

1. The foremost kind of technique or strategy support relates to the set-up of instructive modules goals which vanquish any obstruction amidst school and society for associating instructive modules substance to real living, for passing on 21 st century aptitudes. K-12 learners nowadays are depended upon to make both disciplinary data and $21 \mathrm{st}$ century capacities through regular learning in cutting edge classrooms. Schools are made a beeline for set instructive modules targets which underline the educating of both disciplinary learning and $21 \mathrm{st}$ century aptitudes. They are in like manner made a beeline for interface school instructive projects with society environment; in which schools link learners' formal learning under the instructive modules executed in school and their easygoing learning resounding gathering's present circumstances, and 
meanwhile make campus learning environment direct to community and parents. Governments should thus make approach that definitively announces an instructive modules highlight on 21 st century capacities at national level; and a short time later give schools procedure forces to influence them to sort out 21 st century aptitudes high in elearning course of action and instructive modules transport at school level, re-decode the school instructive projects for an association up with 21 st century capacities, perceive the possible corners for the compromise of 21 st century capacities into instructive modules movement across over different subjects, make instructive modules planning with thought paid to its openness to satisfactory resources and its significance to authentic circumstances for skill progression, and make whole deal school-based game plans that demonstrate their general direction for instructive modules use in modernized classrooms in school education.

2. The second kind of methodology sponsorships relates to the openness of really asserted computing devices and free remote accessibility for making 21 st century aptitudes. As discussed, ICT based classrooms in predictable learning circumstances engage learners' development of 21 st century capacities. Learners in this way require base sponsorships on the engagement in 1:1 learning circumstances and the acquiring of stable Internet system both at home and on campus. As the present school learning environment is not appropriately digitalized, regimes should outfit schools with versatile technique exercises for agreeable work on comprehending the development from physical classrooms for standard data transmission to virtual classrooms for honest to goodness and contextualized learning. Instances of the versatile procedure exercises consolidate financing schools to gather IT base and remote framework for the making of automated classrooms on campus; mobilize parents to outfit learners with individually owned for school learning in the 1:1 learning setting in cutting edge classrooms; and supporting learners to assert individualized computing devices and network connectivity at home for unified learning extended from modernized classrooms.

3. The third sort of technique support relates to the stresses on assurance/legitimate issues in e-learning process in which learning data are being taken after. The related game plan support can address the example of affirmation based approach to manage learning examination, to empower the collection of verification of progress and the working of consideration regarding advance among learners. Learners in cutting edge classrooms learn with modernized sorts of advantages and propelled techniques for correspondence. This learning methodology can be empowered by one-stop digital learning platforms which reinforce learners' useful relationship with learning resources and learning peers, furthermore exact recording and taking after of learning strategy. Governments should in this way reinforce $\mathrm{K}-12$ schools on the association of cutting edge learning platforms which have learning taking after capacity and ponder data security certification in two ways: overseeing K-12 school specialists to pick existing phases of an equivalent kind for school practice, and enabling the IT-related industry to tailor-make digital learning platforms for $\mathrm{K}-12$ schools in their own specific countries or regions. As learners' learning processes are recorded and retrievable on those mechanized learning platforms over a drawn out stretch of time on a cross-platform and cross-country basis, this raises a national and even an overall stress on guaranteeing the assurance and copyrights of learners' learning information. Regimes ought to make a methodology, at national and overall levels, on watching the limit or storage, recuperation and demolish of information on learners' learning shapes in such way.

4. The fourth kind of plan support relates to teacher headway for pre-service and in-service instructors. In cutting edge or ICT classrooms which are beneficial for learner-centered learning, instructors are depended upon to go about as facilitators who watch learners' learning structures and give judicious response. This part would be by and large innovative to most instructors who get used to the part as learning force in routine educator centered perspective for controlling learners' learning in classrooms. This energies the requisite to connect with educators with the capacity to go about as learning facilitators in automated classrooms for making e-learning circumstances and plan elearning practices that propel learners' valid and contextualized learning. Regimes thusly prop up educational institutes and K-12 schools to give preservice educators and in-service educators, exclusively, with attainable and versatile instructor uprising for the stable revolution and execution of teaching exercise alluring for ICT based classrooms in educational institutes.

\section{CONCLUSION}

In the prospective years E-learning in school edification has the objective of making both knowledge domain and 21st century aptitudes amid learners in ICT based classrooms. The productive realization of e-learning hallucination as conferred desires the mutual exertion of three related accomplice groups. In the first place, methodology or strategy makers ought to put exertion as conferred for charting the course forward for more broad and all the more convincing gathering of e-learning in K-12 schools in their schools. Second, the examination bunch ought to effort for the fundamental research problems for propping up the change and dispersal of speculative based e-learning education or resources. Third, the experts in the field, including school pioneers, teachers, people, learners and business partners or stakeholders, ought to place strength in comprehending the e-learning vision. School pioneers need to control targets and progress of elearning programs; instructors must make and complete sound e - learning educational drill; individuals ought to obtain propelled contraptions and e-learning resources for learners' reliable learning after class; learners oblige to acquire with contrasting subject-related automated resources that empower vigorous commitment in significant learning and partner joint effort for making region data and 21 st century aptitudes; and business associates need to outfit schools with support on 
particular settings of software and hardware, furthermore instructive or curriculum modules based e-learning resources. These multiparty and mutual efforts absolutely comfort for the dynamic affirmation of learner-centered learning in cutting edge or ICT based classrooms amid K-12 learners in the school education in the next prospectus years.

\section{REFERENCES}

[1] Padilla, M, Inquiry, process skills, and thinking in science. Science and Children, 48(2), 8-9, (2010).

[2] Trilling et al, 21st century skills: Learning for life in our times. San Francisco, CA: Jossey-Bass (2009).

[3] Saavedra et al, Learning 21st-century skills requires 21 stcentury teaching. Phi Delta Kappan, 94(2), 8-13, (2012).

[4] Szewkis et al, Collaboration within large groups in the classroom. International Journal of Computer-Supported Collaborative Learning, 6(4), 561-575, (2011).

[5] Hoffman, J, What we can learn from the first digital generation: Implications for developing twenty-first century learning and thinking skills in the primary grades. Education 3-13, 38(1), 47-54, (2010).

[6] Rotherham et al, 21st Century Skills: The challenges ahead. Educational Leadership, 67(1), 16-21, (2009).

[7] Claro et al, Assessment of 21st century ICT skills in Chile: Test design and results from high school level students. Computers and Education, 59(3), 1042-1053, (2012)

[8] Gut, D. M, Integrating 21st century skills into the curriculum. In G. Wan \& D. M. Gut (Eds.), Bringing schools into the 21st Century (pp. 137-157). Dordrecht; New York: Springer, (2011).

[9] Hoppe, H. U, Integrating learning processes across boundaries of media, time and group scale. Research and Practice in Technology Enhanced Learning, 2(1), 31-49, (2007).

[10] Alvarez et al, Collboard: Fostering new media literacies in the classroom through collaborative problem solving supported by digital pens and interactive whiteboards. Computers and Education, 63, 368-379, (2013).

[11] So, W. W. M, Creating a framework of a resource-based e-learning environment for science learning in primary classrooms. Technology, Pedagogy and Education, 21(3), 317-335, (2012).

[12] Chan, T. W et al, How East Asian classrooms may change over the next 20 years. Journal of Computer Assisted Learning, 26(1), 28-52, (2010).

[13] Kong, S. C, An evaluation study of the use of a cognitive tool in a one-to-one classroom for promoting classroombased dialogic interaction. Computers and Education, 57(3), 1851-1864, (2011).

[14] Cox, M. J, Formal to informal learning with IT: Research challenges and issues for e-learning. Journal of Computer Assisted Learning, 29(1), 85-105, (2013).

[15] Huang et al, Frontiers of learning technology in a global context. Berlin/Heidelberg, Germany: Springer, (2013).

[16] Milrad et al, Seamless learning: An international perspective on next generation technology enhanced learning. In Z. L. Berge \& L. Y. Muilenburg (Ed.), Handbook of mobile learning (pp. 95-108). New York, NY: Routledge, (2013).

[17] Otero et al, Challenges in designing seamless learning scenarios: Affective and emotional effects on external representations. International Journal of Mobile Learning and Organisation, 5(1), 15-27, (2011).

[18] Wong et al, What seams do we remove in mobile assisted seamless learning? A critical review of the literature. Computers and Education, 57(4), 2364-2381, (2011).

[19] Kicken et al, Design and evaluation of a development portfolio: How to improve students' self-directed learning skills. Instructional Science, 37(5), 453-473, (2009).

[20] Norris et al, A disruption is coming: A primer on the mobile technology revolution. In A. Druin (Ed.), Mobile technology for children: Designing for interaction and learning (pp. 125-139). Amsterdam, The Netherlands: Elsevier Inc, (2009).

[21] Caballero et al, The effects of whole-class interactive instruction with single display groupware for triangles. Computers and Education, 70, 203-211 (2014).

[22] Sims, R, Interactivity and feedback as determinants of engagement and meaning in e-learning environments. In S. Naidu (Ed.), Learning and teaching with technology: Principles and practices (pp. 243-257). Sterling, VA: Kogan Page (2003).

[23] Van Merriënboer et al, Toward a synthesis of cognitive load theory, four-component instructional design, and self-directed learning. Educational Psychology Review, 21(1), 55-66, (2009).

[24] Herrington et al, Authentic learning supported by technology: Ten suggestions and cases of integration in classrooms. Educational Media International, 44(3), 219. 236, (2007).

[25] Niederhauser et al, Addressing the nets for students through constructivist technology use in K-12 classrooms. Journal of Educational Computing Research, 34(1), 91-128, (2009).

[26] Zualkernan, I. A, A framework and a methodology for developing authentic constructivist e-Learning environments, (2006).

[27] Kong, S. C et al, A principle-based pedagogical design framework for developing constructivist learning in a seamless learning environment: A teacher development model for learning and teaching in digital classrooms. British Journal of Educational Technology, 44(6), E209212, (2013).

[28] Nussbaum et al, Special section: Classroom orchestration. Computers and Education, 69, 485-526, (2013).

[29] Dillenbourg, P, Design for classroom orchestration. Computers and Education, 69, 485-492. Ferguson, R. (2012). Learning analytics: Drivers, developments and challenges. International Journal of Technology Enhanced Learning, 4(5/6), 304-317, (2013).

[30] Herrington et al, Authentic tasks online: A synergy among learner, task, and technology. Distance Education, 
27(2), 233-247, (2006).

[31] Herrington et al, Immersive learning technologies: Realism and online authentic learning. Journal of Computing in Higher Education, 19(1), 80-99, (2007).

[32] Long, $\mathrm{P}$ et al, Penetrating the fog: Analytics in learning and education. Educause Review, 46(5), 30-41, (2011).
[33] West, D. M, Big data for education: Data mining, data analytics, and web dashboards. Governance Studies at Brookings, 1-10. Educational Technology and Society, 9(2), 198-212 (2012)

[34] Ferguson, R, Learning analytics: Drivers, developments and challenges. International Journal of Technology Enhanced Learning, 4(5/6), 304-317 (2012). 